\title{
2. O ESTADO, O PODER JUDICIÁRIO E A ADMINISTRAÇÃO PÚBLICA
}

O conceito de Estado é complexo, sendo bastante difícil encontrar uma definição única e precisa, tendo em vista os diversos aspectos que o envolvem. ${ }^{39}$ Também não é objetivo central deste trabalho estabelecê-lo, mas tão somente contextualizar o Poder Judiciário na estrutura do Estado. Por essa razão, serão mencionados alguns conceitos que visam dar uma noção a respeito do tema.

Dalmo Dallari conceitua Estado como a "ordem jurídica soberana que tem por fim o bem comum de um povo situado em determinado território". ${ }^{40}$ Hely Lopes Meirelles prefere fazer referência às diversas definições, conforme o aspecto considerado:

\begin{abstract}
Do ponto de vista sociológico, é corporação territorial dotada de um poder de mando originário (Jellinek); sob o aspecto político, é comunidade de homens, fixada sobre um território, com potestade superior de ação, de mando e de coerção (Malberg); sob o prisma constitucional, é pessoa jurídica territorial soberana (Biscaretti di Ruffia); na conceituação do nosso Código Civil, é pessoa jurídica de Direito Público Interno (art. 14, I) [...] Esse é o Estado de Direito, ou seja, o Estado juridicamente organizado e obediente às suas próprias leis. ${ }^{41}$
\end{abstract}

Para que o Estado cumpra sua finalidade de alcançar o bem comum do povo, atendendo às necessidades públicas, mantendo a ordem jurídica e realizando todos os demais atos para os quais foi criado, é necessário que se organize e que tenha uma estrutura por meio do qual se possam operacionalizar essas ações. Pelas razões já expostas, há uma diversidade muito grande na forma pela qual ocorre essa organização, havendo diferenças mais e menos significativas entre os diversos Estados, tendo em

\footnotetext{
39 "Encontrar um conceito de Estado que satisfaça a todas as correntes doutrinárias é absolutamente impossível, pois sendo o Estado um ente complexo, que pode ser abordado sob diversos pontos de vista e, além disso, sendo extremamente variável quanto à forma por sua própria natureza, haverá tantos pontos de partida quantos forem os ângulos de preferência dos observadores" (DALLARI, Elementos..., p. 115). "Devido à variedade de objetos que o termo comumente denota, definir 'Estado' torna-se difícil" (KELSEN, Teoria geral..., p. 261).

${ }^{40}$ Elementos..., p. 118.
} 
vista a multiplicidade de fatores de ordem política, cultural, geográfica, econômica etc. que exercem influência na formação do Estado, impedindo que existam estruturas idênticas. No entanto, ainda que sejam diversas, essas estruturas são necessárias para dar existência concreta ao Estado.

Já a Administração Pública compreende o conjunto de pessoas, órgãos, agentes e demais instrumentos por meio dos quais o Estado exerce suas funções, realizando as ações para cumprir suas finalidades. ${ }^{42}$ Assim, o Estado, enquanto pessoa jurídica de direito público, está estruturado na Administração Pública, que lhe fornece os meios concretos para sua existência efetiva.

No âmbito territorial, alguns Estados adotam o regime federativo, estabelecendo uma divisão do poder que prevê uma organização estruturada nacionalmente, com atribuições próprias e atuação em todo o território nacional, e organizações regionais, que podem também existir em nível local. ${ }^{43}$ Criam-se, como no Brasil, várias esferas de governo, cada qual dotada de personalidade jurídica própria, com sua Administração Pública voltada para cumprir as atribuições que lhe foram destinadas pela Constituição. No Brasil, por conseguinte, podemos identificar a Administração Pública Federal, as Administrações Públicas Estaduais, a Administração Pública Distrital e as Administrações Públicas Municipais. Isso revela a existência da chamada "divisão vertical" da Administração Pública brasileira. ${ }^{44}$

Quanto às funções que o Estado exerce, como visto no capítulo anterior, estabeleceu-se a separação em três poderes, devendo cada um - Legislativo, Judiciário e Executivo - exercer, predominante e respectivamente, as funções de elaboração das leis,

\footnotetext{
${ }^{41}$ Direito Administrativo brasileiro, p. 55-6.

${ }^{42}$ Trata-se de uma conceituação simplificada, destinada a atender aos objetivos do trabalho para este momento em que se faz necessária a inclusão do Poder Judiciário no contexto da Administração Pública. A definição precisa de Administração Pública também não é tarefa simples. "Sempre houve dificuldade em fixar com precisão o conceito de Administração Pública. Diz-se mesmo que a Administração se deixa descrever, mas não se deixa definir, sobretudo ante sua complexidade e caráter multiforme de suas atuações" (MEDAUAR, Direito administrativo moderno, p. 44).

${ }^{43}$ A questão do federalismo é bastante interessante e permite extensas discussões, parte das quais já abordamos na obra Federalismo fiscal e fundos de participação. Não é o caso, no entanto, de se estender o assunto neste momento, a fim de que não se desvie do objeto principal da discussão, razão pela qual se faz esta referência sucinta.

${ }^{44}$ MEDAUAR, Direito..., p. 50.
} 
interpretação das leis (e solução de conflitos) e aplicação das leis, tornando-as eficazes nos casos concretos. ${ }^{45}$

A Administração Pública é muitas vezes vista como a estrutura sob a qual se organiza o Poder Executivo, uma vez que este é responsável por exercer o que se pode chamar de função administrativa. No entanto, tal forma de ver a Administração Pública não se torna coerente com o que se constata na prática, ao se analisarem os aspectos administrativos e financeiros do Estado brasileiro.

O orçamento público é único para cada uma das Administrações Públicas (federal, estaduais, distrital e municipais), e nele estão previstas as receitas e as despesas de todos os órgãos que as compõem. Pela classificação institucional (ver item 4.3.2 deste trabalho), as receitas e as despesas são previstas para cada um dos poderes (Executivo, Legislativo e Judiciário, sendo este último válido apenas para as Administrações federais e estaduais, uma vez que não há Poder Judiciário na esfera municipal), órgãos e unidades que os integram. Assim, fica claro que, no aspecto financeiro, o Poder Judiciário integra a Administração Pública. A Lei de Responsabilidade Fiscal (Lei Complementar $n^{0} 101$, de 2000) também evidencia essa situação ao estabelecer, no art. $1^{\mathrm{o}}, \S 3^{\circ}$, I, que, quando se fazem referências às pessoas jurídicas da união, aos Estados, ao Distrito Federal e aos Municípios, elas compreendem o Poder Executivo, o Poder Legislativo (nestes abrangidos os Tribunais de Contas), o Poder Judiciário e o Ministério Público.

Também no âmbito administrativo constata-se que o Poder Judiciário integra a Administração Pública, uma vez que, ressalvadas suas peculiaridades, os princípios e as normas da Administração Pública aplicam-se ao Poder Judiciário, quer no aspecto organizacional, quer no que se refere ao funcionalismo público que presta serviços a este Poder, bem como em outros aspectos. A redação do art. 37 da CF é bastante clara nesse sentido: “A administração pública direta e indireta de qualquer dos Poderes da união, dos Estados, do Distrito Federal e dos Municípios obedecerá aos princípios de legalidade, impessoalidade, moralidade, publicidade e eficiência”.

\footnotetext{
45 Aqui também se faz referência simplificada às funções de cada um dos Poderes, uma vez que não se pretende abrir discussão sobre esse ponto neste momento do trabalho.
} 
O Poder Judiciário, portanto, integra a Administração Pública, sem, no entanto, fazer parte do Poder Executivo, evidenciando não ser lógico considerar a Administração Pública como estrutura do Poder Executivo. A Administração Pública é a estrutura por meio da qual o Estado (e não o Poder Executivo) organiza-se a fim de atender aos interesses públicos.

A contextualização do Poder Judiciário na Administração Pública comporta ainda considerações acerca da personalidade jurídica.

No ordenamento jurídico brasileiro, as pessoas jurídicas podem ser de direito público, interno ou externo, e de direito privado (Código Civil, art. 40). As pessoas jurídicas de direito público interno são a união, os Estados, o Distrito Federal, os Territórios, os Municípios, as autarquias e as demais entidades de caráter público criadas por lei (Código Civil, art. 41).

Há consequências importantes para aqueles que têm personalidade jurídica, como o fato de tornarem-se civilmente responsáveis por atos de seus agentes que causem danos a terceiros (Código Civil, art. 43).

O Poder Judiciário, assim como os Poderes Legislativo e Executivo, não são pessoas jurídicas. São órgãos que compõem a Administração Pública ${ }^{46}$, que, por sua vez, corresponde à materialização da estrutura do Estado, este, sim, dotado de personalidade jurídica, constituindo-se em uma pessoa jurídica de direito público interno, nos termos do art. 41 do Código Civil. As palavras de Hely Lopes Meirelles são esclarecedoras:

Os órgãos integram a estrutura do Estado e das demais pessoas jurídicas como parte desses corpos vivos, dotados de vontade e capazes de exercer direitos e contrair obrigações para a consecução de seus fins institucionais. Por isso mesmo, os órgãos não têm personalidade jurídica nem vontade própria, que são atributos do corpo e não das partes, mas na área de suas atribuições e nos limites de sua competência funcional expressam a vontade da entidade a que pertencem e a vinculam por seus atos, manifestados através

\footnotetext{
${ }^{46}$ Os órgãos públicos "são unidades de atuação, que englobam um conjunto de pessoas e meios materiais ordenados para realizar uma atribuição predeterminada", e a expressão deve ser adequadamente utilizada para "designar unidade de atuação integrante de uma pessoa jurídica" (MEDAUAR, Direito..., p. 54-5). Maria Sylvia Di Pietro, ao classificar os órgãos públicos quanto à posição estatal, inclui os Tribunais na categoria de órgãos independentes, originários da Constituição e representativo de um dos três Poderes (Direito..., p. 302).
} 
de seus agentes (pessoas físicas). ${ }^{47}$

Os agentes do Poder Judiciário agem em nome da pessoa jurídica que representam, podendo ser a união, os Estados ou o Distrito Federal. Um Juiz federal integra o Poder Judiciário federal, órgão da união; um Juiz de direito do Estado de São Paulo integra o Poder Judiciário desta unidade da federação, que é órgão da pessoa jurídica de direito público interno "Estado de São Paulo".

As consequências jurídicas são da pessoa jurídica que integram, e não do Poder Judiciário, que não responde juridicamente por seus atos, uma vez que não tem personalidade jurídica.

O Poder Judiciário, por meio dos órgãos nos quais se subdivide (Tribunais, por exemplo), pode manter relações com terceiros, tais como celebração de contratos, produzindo efeitos jurídicos. Essa atuação, no entanto, faz-se mediante uma relação de imputação, como Hely Lopes Meirelles nos ensina:

Embora despersonalizados, os órgãos mantêm relações funcionais entre si e com terceiros, das quais resultam efeitos jurídicos internos e externos, na forma legal ou regulamentar. $\mathrm{E}$, a despeito de não terem personalidade jurídica, os órgãos podem ter prerrogativas funcionais próprias que, quando infringidas por outro órgão, admitem defesa até mesmo por mandado de segurança.

A atuação dos órgãos é imputada à pessoa jurídica que eles integram, mas nenhum órgão a representa juridicamente. A representação legal da entidade é atribuição de determinados agentes (pessoas físicas), tais como os Procuradores judiciais e administrativos e, em alguns casos, o próprio chefe do Executivo (CPC, art. 12, I, II e VI). Não se confunda, portanto, a imputação da atividade funcional do órgão à pessoa jurídica com a representação desta perante a Justiça ou terceiros: a imputação é da atuação do órgão à entidade a que ele pertence; a representação é perante terceiros ou em juízo, por certos agentes.

Não há entre a entidade e seus órgãos relação de representação ou de mandato, mas de imputação, porque a atividade dos órgãos identifica-se e confunde-se com a da pessoa jurídica. Daí por que os atos dos órgãos são havidos como da própria entidade que eles compõem. Assim, os órgãos do Estado são o próprio Estado compartimentado em centros de competência, destinados ao melhor desempenho das funções estatais. Por sua vez, a vontade psíquica do agente (pessoa física) expressa a vontade do órgão, que é

${ }^{47}$ Direito Administrativo brasileiro, p. 64. 
a vontade do Estado, do Governo e da Administração. ${ }^{48}$

A separação de poderes, princípio erigido à condição de cláusula pétrea, acompanhada da autonomia administrativa e financeira reconhecida pelos arts. 99 e 168 da CF, exige uma maior reflexão, pois permite vislumbrar a possibilidade de conflito interno entre órgãos da Administração Pública, uma vez que passam a existir interesses próprios de cada Poder.

O fato de não ter personalidade jurídica não afasta a possibilidade de órgãos da Administração Pública serem dotados de personalidade judiciária, conferindo-lhes legitimidade processual para defenderem seus interesses em juízo.

Existindo interesses de um Poder que possam ser conflitantes com os interesses de outro Poder, não se mostra compatível, ante o princípio da separação dos poderes, que a decisão, em todos os casos, seja tomada no âmbito interno, pois não há superioridade hierárquica de um Poder sobre o outro. Também não se pode atribuir ao Poder Executivo, por meio de seus órgãos, como uma Procuradoria, a defesa dos interesses de um outro Poder em juízo em caso de conflito, quando esse conflito puder ocorrer contra o próprio Poder Executivo.

É necessário, pois, que os poderes, ou mesmo os órgãos que os compõem, tenham legitimidade para demandar em juízo nas causas de seu interesse, quando se mostrarem conflitantes com os interesses dos demais poderes, caso em que não se pode reconhecer presente a correspondência entre a vontade do órgão e a vontade do Estado.

O próprio Hely Lopes Meirelles reconhece a capacidade processual de órgãos de Poder, ao se manifestar sobre a Câmara de vereadores:

\footnotetext{
A capacidade processual da Câmara para a defesa de suas prerrogativas funcionais é hoje pacificamente reconhecida pela doutrina e pela jurisprudência. Certo é que a Câmara não tem personalidade jurídica, mas tem personalidade judiciária. Pessoa jurídica é o Município. Mas nem por isso se há de negar capacidade processual, ativa e passiva, à Edilidade, para ingressar em juízo quando tenha prerrogativas ou direitos próprios a defender. ${ }^{49}$
}

\footnotetext{
${ }^{48}$ Idem, p. 64-5.

${ }^{49}$ Direito Municipal brasileiro, p. 434.
} 
A jurisprudência brasileira é farta em exemplos de aceitação da capacidade processual dos órgãos de Poder, principalmente como impetrantes de mandados de segurança (MS 23.277/AL, MS 24.206-MC/AP, MS 24.380/RO, todos do STF), mas também em ações ordinárias (AO 1.042-MC/PE, STF) e ações diretas de inconstitucionalidade (ADIn 732-7/RJ, STF). Vale transcrever trechos de decisão do Tribunal de Justiça da Paraíba, que deixam claros os argumentos expostos:

\begin{abstract}
A personalidade jurídica não se confunde com a personalidade judiciária; esta é um minus em relação àquela. Toda pessoa jurídica tem, necessariamente, capacidade processual, mas órgãos há que, embora sem personalidade jurídica, podem estar em juízo, em seu próprio nome, na defesa de prerrogativas ou direitos próprios, porque são titulares de direitos subjetivos perceptíveis de proteção judicial, quando relegados ou contestados. Nessa situação se encontra o Tribunal de Contas que, não tendo personalidade jurídica, tem, contudo, personalidade judiciária, ativa e passiva.
\end{abstract}

No corpo do acórdão, o relator esclarece ainda em seu voto:

\begin{abstract}
No âmbito estadual, quem tem personalidade jurídica é o Estado, que não se confunde com o Poder Executivo, porque este é apenas um minus daquele. $\mathrm{O}$ Estado são os Poderes Legislativo, Executivo e Judiciário, com os seus órgãos. Assim, a rigor quem deve estar em juízo, propugnando pela defesa de seus interesses, situados em quaisquer de seus entes, é o Estado, através da Procuradoria-Geral. Não assim o Legislativo, o Executivo ou o Judiciário ou o Tribunal de Contas. No caso presente, embora o Tribunal de Contas não tenha personalidade jurídica, cabe-lhe, no entanto, deduzir o pedido exordial, como o fez, pois tem capacidade judiciária para tanto, visto que está agindo na defesa de prerrogativas funcionais, como já acentuado. ${ }^{50}$
\end{abstract}

Na doutrina, a posição não tem sido diferente. Regis Fernandes de Oliveira é claro ao concluir: "O Judiciário, no exercício de suas atribuições constitucionais, tem capacidade para ir a juízo e postular que sejam resguardados seus direitos, no cumprimento de suas obrigações". 51

Fernando Guimarães Ferreira, em artigo dedicado ao tema, expõe com clareza seus argumentos, trazendo fundamentos de doutrina e jurisprudência que não deixam margem a dúvidas sobre a personalidade judiciária dos órgãos de Poder, dotados de

\footnotetext{
50 TJPB, Decret. 93.006464-5, j. 9.6.1993, rel. Des. Antonio Elias de Queiroga, Revista dos Tribunais $701 / 142$

${ }^{51}$ A Constituição assegura autonomia do Judiciário.
} 
capacidade processual para demandar em juízo, ativa e passivamente, na defesa de seus interesses. Conclui seu trabalho asseverando que:

a) a Constituição Federal (1988), dentro do processo de redemocratização nacional - como reação ao centralismo da Emenda Constitucional n. 1 de 1969 -, alterou de forma substancial o conteúdo dos princípios da autonomia e da independência dos Poderes, no que tange ao exercício das prerrogativas próprias de cada um desses, sendo concedida aos Poderes Judiciário e Legislativo uma autonomia administrativa e financeira antes concentrada no Poder Executivo (hipertrofia do Poder Executivo), de forma que o entendimento pela capacidade processual absoluta desses Poderes não encontra seu pressuposto de validade no atual diploma constitucional, além de representar sério risco ao fortalecimento da democracia no País, uma vez que estes Poderes não teriam a possibilidade de defender, de forma real e efetiva, suas prerrogativas, constitucionalmente previstas; e b) a jurisprudência nacional - inclusive do Supremo Tribunal Federal - bem como a doutrina nacional são vastas ao reconhecer, expressamente, aos Poderes Judiciário e Legislativo - mesmo anteriormente à Constituição Federal de 1988 -, personalidade judiciária (capacidade processual), por titularem direitos subjetivos públicos, podendo comparecer em juízo, em qualquer espécie de ação judicial para a defesa de suas autonomias e prerrogativas institucionais, as quais foram alargadas pelo novo diploma constitucional federal. ${ }^{52}$

O Poder Judiciário, por conseguinte, embora não tenha personalidade jurídica, é dotado de personalidade judiciária, tendo capacidade processual para estar em juízo na defesa de seus interesses específicos.

${ }^{52}$ A consolidação..., p. 183-4. 